J0J

\title{
Laser Replaces Scalpel in Surgery with Cost Reduction how Shows Prostate Therapy
}

(Nesa Days 2015 Conference, Berlin)

\author{
Hans Hainz* \\ Member/Laser: DGLM/ASLMS/(EMLA ExC), D53359, Rheinbach, Germany
}

Submission: December 15, 2015; Published: February 24, 2016

*Corresponding author: Member/Laser: DGLM/ASLMS/(EMLA ExC), D53359, Rheinbach, Germany, Email: hhhainz@gmx.de

\section{Poster Presentation}

This presentation concerns global super anunation with demand of modern minimal invasive and soaring prices. Well as old urologist shown by prostate therapy.

Germany 1998. Today 7 newborn on 1000 inhabitants and $1,3,4$ babies on every woman last place global. Every $4^{\text {th }}$ man is over 60 years $+5 \mathrm{Mil}$ have prostate problems. Place Nr1 in male tumor statistic are $70000 \mathrm{CaP} / \mathrm{y}$ followed by Urothel CA on place 3. Threatening is increase of malignancies everywhere; eg. China statistical Yearbook 2008 accounted 28\%cancerdeath. EU Cancer Congress Vienna 2012 reported diagnosis and therapy needed in 2009130 billion Euro -this numeral is soaring.

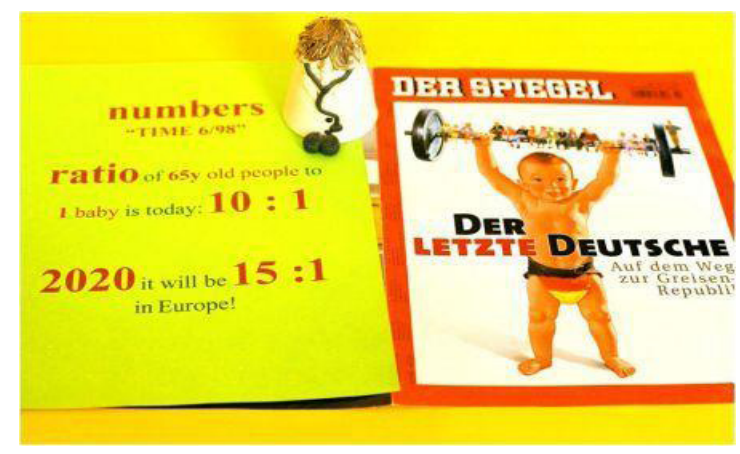

Urology began in Pharaos times as bladder catherisation with silver grove sounds or peacocks quills: The time between let me be silent Anesthesia enabled 1905 Freyer OP - by help of Morse code and under secables directly performed everywhere.

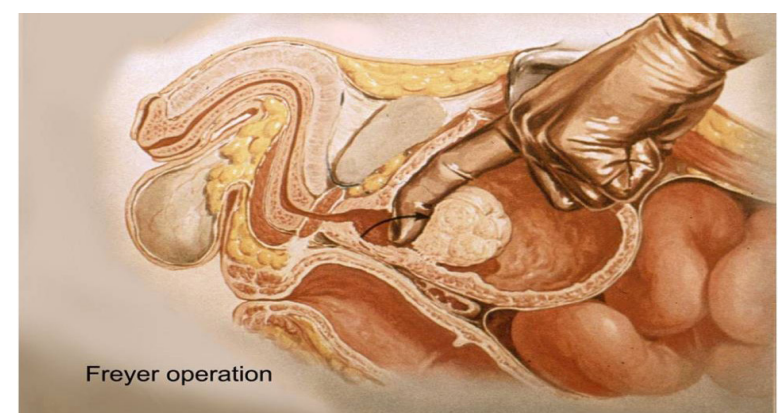

Urologists dream to use the natural urinary channel system for diagnosis realized 1841 Nitsche's cystoscope with a simple metalic tube, candles and a concave mirror on the forehead. Parallel Italian colleagues in Pisa pushed transurethral an isolated copper wire until obturation stoped it and prostate enlargment was burned by electricity with Leydener bottle.

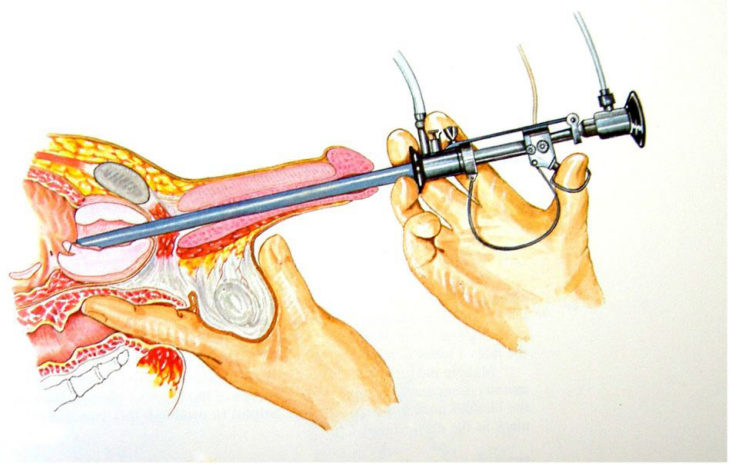

Combining both ideas with Edison's mini electro bulbs, rodoptics and platin loops 1920 TURP was possible. After integrating glas fibres and electrotomes with transistors 1970 open BPE-surgery was replaced and all kinds of waves were tested. Laser leaded.

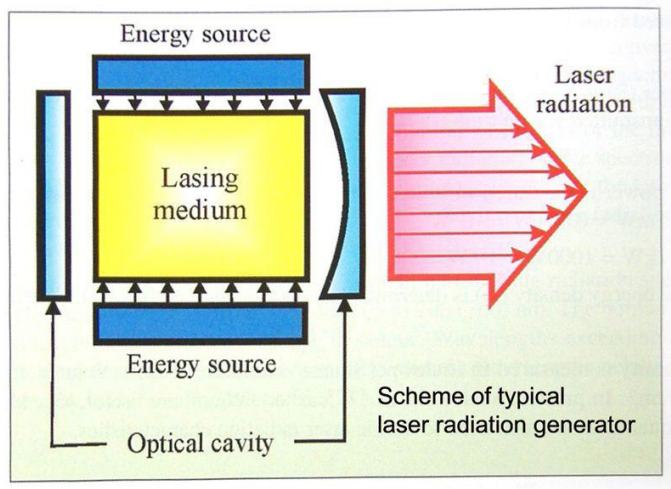

Here principle with liquid laser medium e.g. Scotish, Whisky. Electric bulbs work around this glass bottle. Electrons are lifted 
on so called instable orbit. Returning to normal position photons are emitted and inserted by convex lens into bare fibre. Today solid elements are used.

\section{Einstein declared " $\mathrm{E}=\mathrm{mc}^{2}$ "}

He translated in language" materia is immense energy" $v$ Atomicbomb 1945 With 500gr enriched uranium 235 proved it in Hiroshima. Outlines of people were drawn into the pavement without particles of bones left behind. That led to lasertheory 1954 published West by Gordon/-Townes simultaneously Prochorow East and 6 years later to Maymans lasermachine.

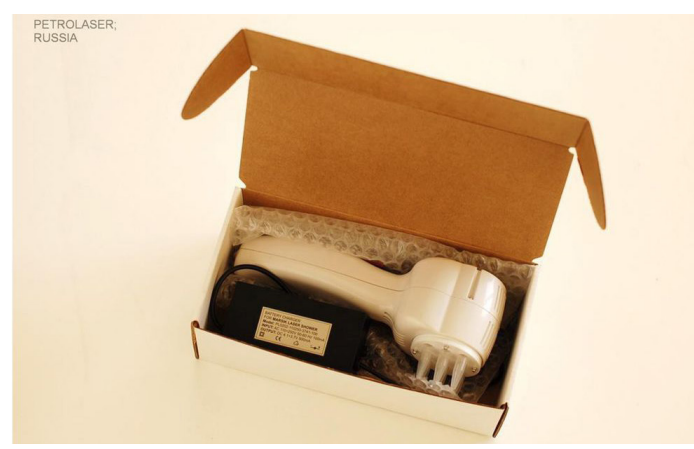

Surgery needs power.

Progress in technology enabled first livertumorOP 1983 by SteveG.Bown/-London. Core is the use of

Glass fibres for coagulation, carbonisation, vaporisation and atomic photo ablation in tissue, teeth and bones of humen and animals. Russian Colleagues began directly biostimulation (LLLT) with low costs at diabetes, hypertony a.s.o; today 10000 laserdoc work in 40500 bed laser clinics. For hometherapy patients take these instruments. German prefered pharmacy and paid for it in 201234 billion Euro of our 165 billion social insurance health budget.

After finding x-bosom (Higgsfield) 2012 -in Large Hadron Collider(CERN) old greek-philosophical atom is in universe all electromagnetic loading $\left(\mathrm{m}=\mathrm{E} / \mathrm{c}^{2}\right)$ : Below now standard model Thus laser scalpel measures in reflected beam at Cancer Clinic Moscow when you come in or out of tumor and shows histology by Raman Spectroscopy that all makes the paradigm-shift in surgery.

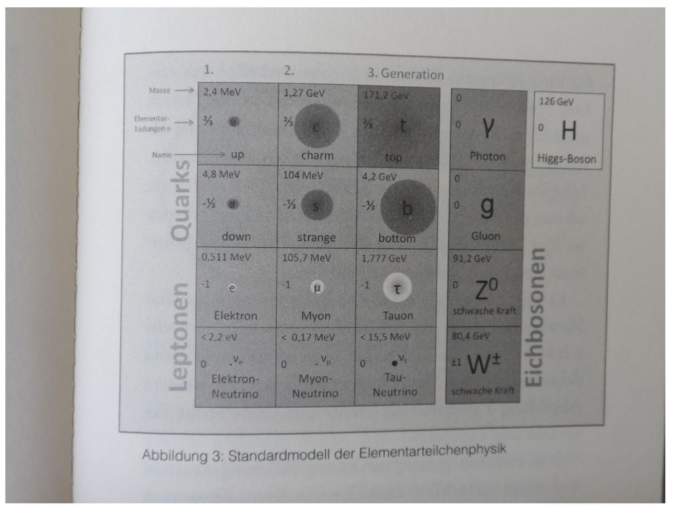

Costs are the pinpoint for realization.

This and next: 2 tables for an <inguinal scalpel Incision>. As simple visual proof for change in surgery.

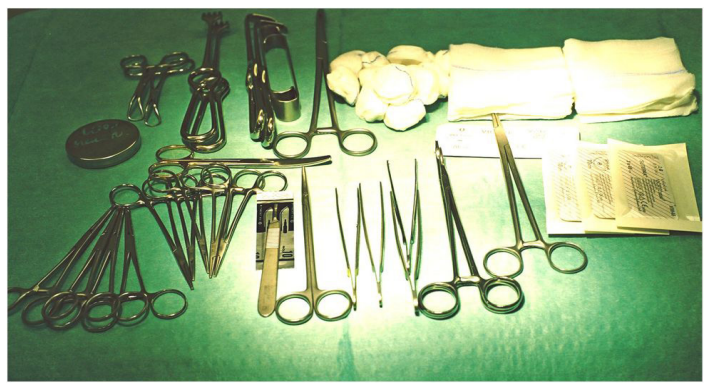

Here laser for same operation. What cannot be seen is less bleeding, infection, pain and timesaving multi tool function with cost reduction. A new 980nm60WDiodelaser enabled us 1996 $90 \%$ of open and all trans-urethral surgery reducing our costs to $40 \%$ of pre-laser era.

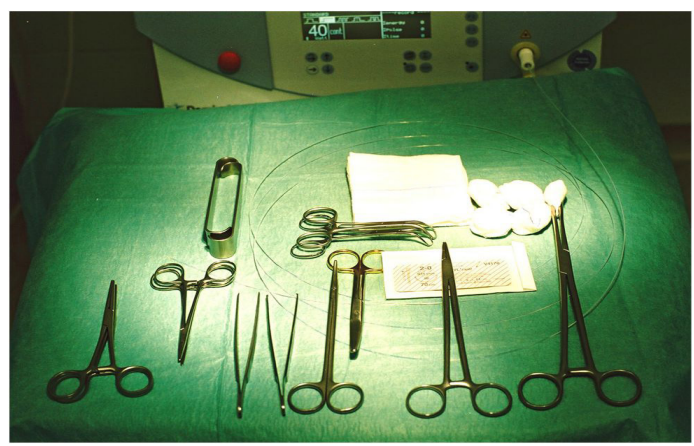

Innovation has its price: Single use products like sutures, mull a.s.o. cost in Freyer about $5 €$; they raised to $50 €$ in TURP by precious platin loops and soared once more ten times in all heat therapy, operating by wire with multi branch robots to $1000 €$ and more.

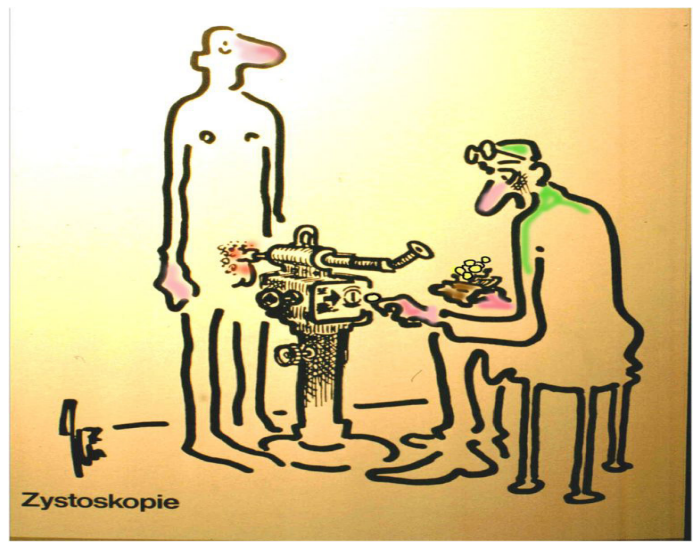

This new small Da Vinci was in TIME July 6-13 2015. Regarding it together with our Y-generation, in working hand grown in a smart phone containing <cloud $>$ and Encyclopedia Britanica - it could be that Intuitive Surgery(the producer) shows here "the surgeon 4.0 " analog cars 4.0 that move without 
driver. Please look right: hands without instruments - atypical for surgeons

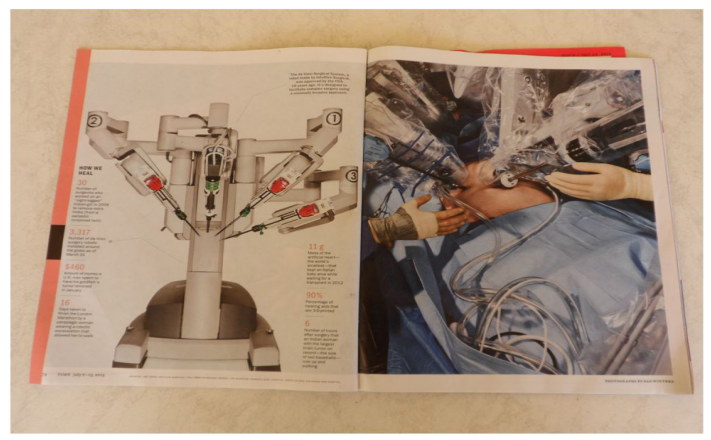

A dispersion of long distance monochromatic beam make perfect special fibres. But by continues work in tissue with re sterilized fibres broken off glass particles shape a kind of irregular golf ball surface that scatters ray very inexpensive. With these $0,6 \mathrm{~mm}$ bare-fibres, a NdYAG Siemens Medilas 100 and $17,5 \mathrm{Ch}$. Olympus urethra scope we lasered via the guide tube since 1988 lege artis more than 4000 bladder tumour.

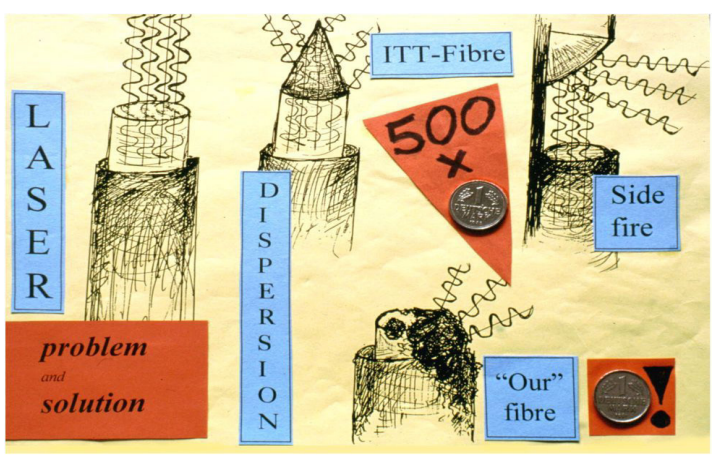

First prostate laser operation 1991 Hof stetters ILCP with 20W-NdYAG and costly special ITT fibres stopped fast. So we used 1993 this set for Coagulation of prostate. With 40Wcw NdYAG we burned non contact mode into every treatment point 1000 Joules in a grid of about $5 \mathrm{~mm}$. Our fibres made a slump from about 500 USD to 1 USD and we were faster as ILCP. Real problem was publishing this experiment.

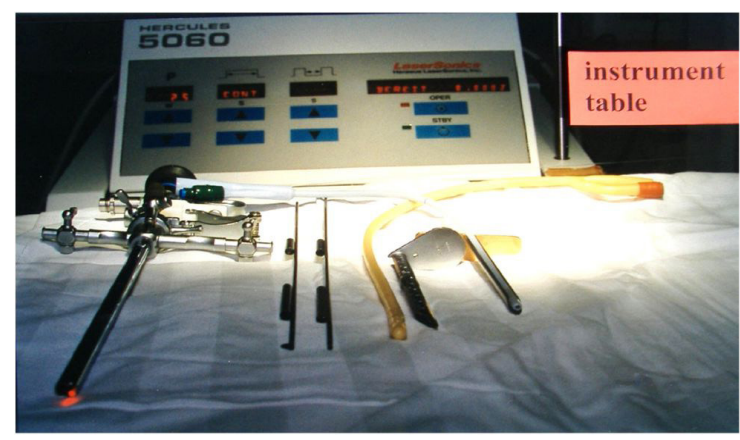

Belgian Colleagues helped us at the 7thVideo Urology World Congress/-Antwerp June 1996: Our equipment made a 5 -8mm- diameter coagulation cylinder with a depth of about 1,4 $\mathrm{cm}$ so big adenoma needs more sessions. But it was the lowest complication rate we ever had in 391 cases besides fever only $7 x d i r e c t$ bleedings lasering directly at micturation failure and $4 \mathrm{x}$ necrotic tissue as micturation failure.
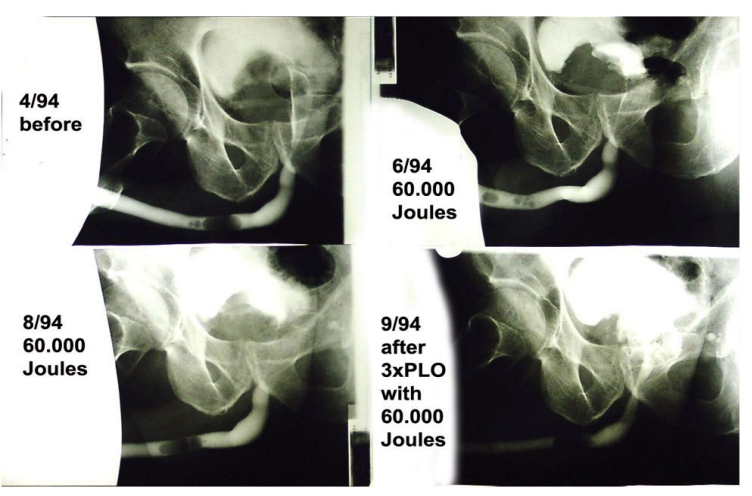

We looked for better techniques. They had specific complications shown here in red or blue. The combination first invasive coagulation for less bleeding followed by cutting to get early voiding was as fast as TURP and we had luck to present it 21 national, 23 international +10 world Congresses

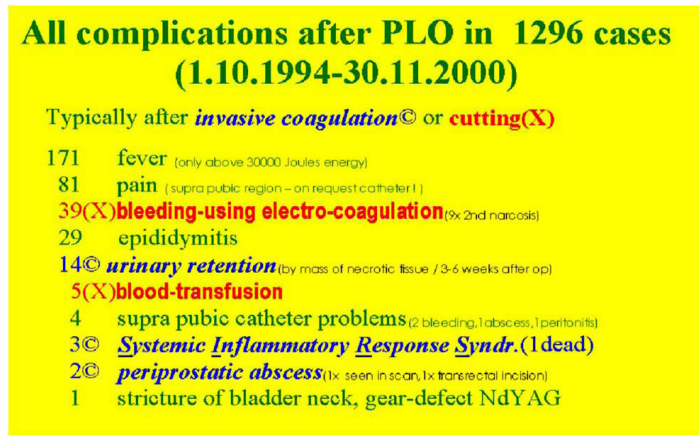

Here a sketch with instructions. With modern flexible endoscopes we can laser the same way in humans and animals. Otherwise by aid of modern imaging systems and Seldinger function fibres reach within small double tube-succer nearly any spot in the body and we laser exactly the area. Drain enables photo dynamic therapy in Oncology.

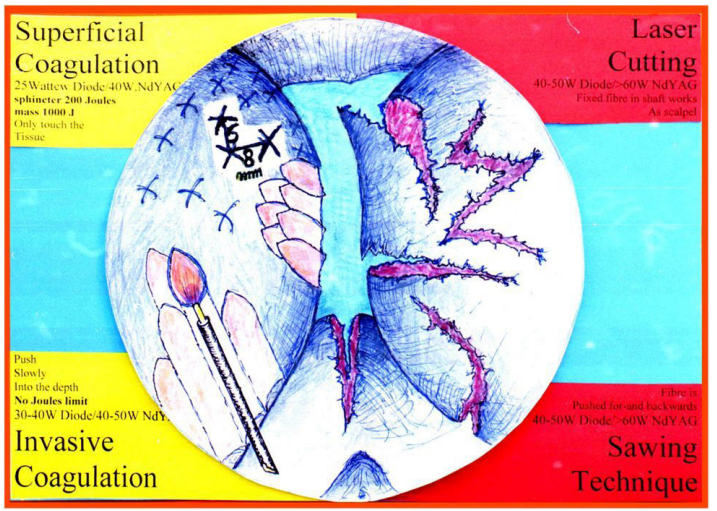

First Photo selective Vaporization of Prostate (PVP) Malek \&-Kuntzman/MayoClinic 1998: Energy increase by 
80W-KTP-Laser enabled it. Tissue is rend in tiny pieces and disappears bloodless in a veil of small air bubbles. In this way a new anatomical ground results without carbonization zone. PVP is in USA performed in 80\%of all BPE-Op 2011 - mostly as outpatient therapy- a new standard. 2014 French Colleagues declared Urology in progress PVP best for all prostate sizes and high risk men under anticoagulation therapy

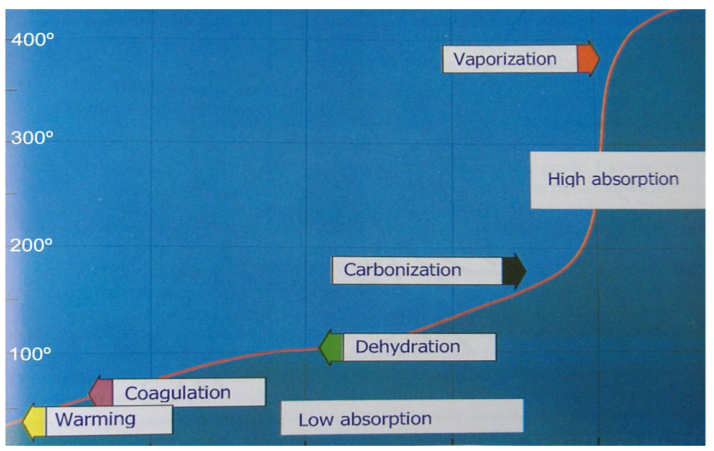

Several similar results in pathology let us guess that early malignant cell population makes early metastatic diseases. That's why we propose at first prostatic symptoms and completed family planning today with visual device vaporization into anatomical capsule of prostate - as long as we have no causal therapy of Cap and in BPE.

\section{CaP autopsy study after accident of 162 men aged 20-80 \\ Sanchez-Chapado ( Prostate 2003; 54(3) : 238 - 247) \\ Age Number AdenoCA HGPIN \\ below 40y! $60 \quad 4 \quad 5$ \\ above $70 \quad 27 \quad 9$}

One man had CaP with 23 years!
The $3^{\text {th }}$ World profits to come with laser directly to modern surgery without passing

Last century developed methods e.g. our friends - laser surgeons in Dhaka/Bangladesh: Prove of next pictures

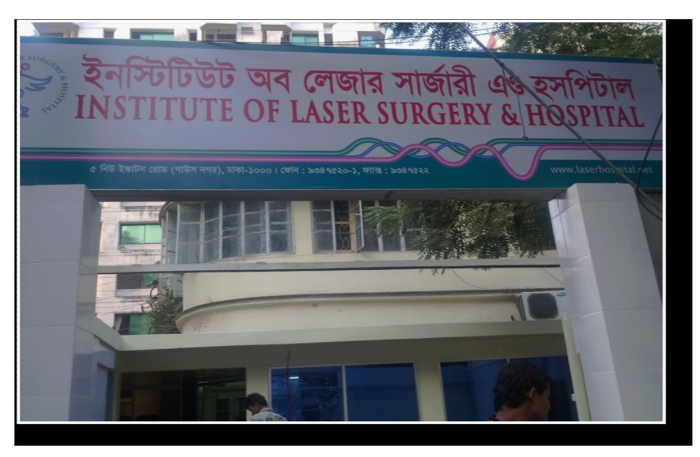

